\title{
Editorial
}

\section{Studies of Suicidal Behavior Using National Registers}

\section{An Adventure Without Boundaries?}

\author{
Annette Erlangsen ${ }^{1,2,3}$, Ping Qin ${ }^{4}$, and Ellenor Mittendorfer-Rutz ${ }^{5}$ \\ 'Danish Research Institute for Suicide Prevention, Mental Health Centre Copenhagen, Hellerup, Denmark \\ 2Department of Mental Health, John Hopkins Bloomberg School of Public Health, Baltimore, MD, USA \\ ${ }^{3}$ Centre for Mental Health Research, Australian National University, Canberra, Australia \\ ${ }^{4}$ National Center for Suicide Research and Prevention, Institute of Clinical Medicine, University of Oslo, Norway \\ ${ }^{5}$ Department of Clinical Neuroscience, Division of Insurance Medicine, Karolinska Institutet, Stockholm, Sweden
}

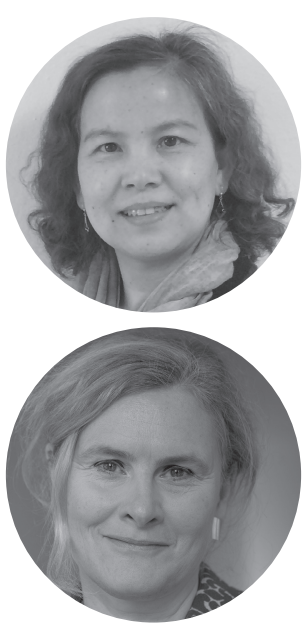

Administrative databases, often with a national coverage, have in many countries proven their value as a data source for research in public health, especially in areas where fatal outcomes, such as death by suicide, prevent direct data collection. While many countries collect national data on vital events, fewer countries maintain a national database on health-care provision and socioeconomic information. The possibility of linking data from different databases for each individual is one of the key components in this type of research. In some countries this has been achieved through a unique identification (id) number, which has advantages over linkage based on personal markers, such as date of birth and name, as these are less likely to secure a complete linkage.

Nordic register data have, in this respect, contributed substantially to the knowledge base on suicidal behavior. Given that the Nordic experience may be of relevance for other entities contemplating similar systems, this editorial offers a brief overview of the personal id number and the rationale for its use in Nordic countries. The authors identify some of the main contributions from register-based data to suicide research in terms of studies of risk predictors and evaluations of interventions. The strengths and limitations of register-based data are presented along with an exploration of future venues for research. The experiences gained for a suicide research perspective might be of interest to foreign entities who are contemplating to access the Nordic registers.

\section{One Number}

The key element in the Nordic registers is the personal identification (id) number. The personal id number is not a new invention; in 1947, the Swedish parliament introduced a personal id number for all citizens. This was used as the backbone in a computerized Swedish population register in 1967 (Ludvigsson, Otterblad-Olausson, Pettersson, \& Ekbom, 2009). Shortly after, the other Nordic countries followed suit and a similar id number and system were implemented in Norway in 1964, in Denmark in 1968, and in Finland in 1969 (Population Register Centre, Finland, 2018; Kompetansesenter for IT i helsevesenet, 2010; Nielsen, 1991). Iceland had already introduced a personal id number in 1952 but later opted for a name number that was then replaced by a 10-digit number in 1980 (Watson, 2010).

The introduction of personal id numbers meant that each citizen was given an id card listing his/her personal id number, and all newborns from this date on were assigned a number at birth. Persons migrating into the country were also given an identifier. Each Nordic country uses a different system and travelers between Nordic countries receive a different number in each country. Still, some similarities exist; the 10-11-digit number includes the person's birthdate and a marker for male or female sex. Each id number is unique in the sense that no duplicates exist and persons leaving the country maintain the same id number upon re-entry. Over recent decades, it has become possible to have one's id number changed, for instance, in cases of identity theft or for persons who change their sex.

The intention of the id number was to have a better way of administering tax payments accompanied by a wish to 
replace punch cards with the newly available options for electronic data processing in the late 1960s. However, across the public sector several administrative systems quickly began using the identifier, including population, housing, hospital, and death registers, and its use has been mandatory for contacts with public authorities and services since the 1970s. It could be argued that the social welfare state with free public health care, numerous social transfer payments, and other public services provided an ideal setting for population-based registers. Still, at that time probably no one realized that this would signify the beginning on a new era of public health research. Today, the main health-related registers include nationwide data on all hospital admissions, prescriptions, clinical laboratory tests, and general practitioner visits, which can all be linked to high-quality, clinical databases on specific health conditions and disorders.

\section{Studies on Suicidal Behavior}

Much of the knowledge base in suicide research has been formed by clinical investigations, psychological autopsy studies, community-based sample surveys, and register-based studies. While clinical databases might provide more detailed data on biomarkers and scores from psychological scales and the psychological autopsy studies gather information on traits and symptoms prior to death, representativeness and the possibility of data linkage are the main advantages of register-based data. Register-based studies allow for very long follow-up times and large databases enable subgroup analyses (Mittendorfer-Rutz, Rasmussen, \& Wasserman, 2004). Moreover, clinical studies on the prognosis after a suicide attempt are challenged by the often low rate of compliance to treatment of this patient group. Here, the registers can contribute considerably to the existing knowledge base as studies have practically no loss to follow-up (Niederkrotenthaler et al., 2014). Although many countries keep national databases, for instance, of causes of death, these do not always allow for individual-level linkage to other databases. As a consequence, studies using these data might submit to ecological fallacy by being based on associations of aggregate data. Interestingly, multilevel analysis has shown that while aggregate-level data, such as area measures on unemployment rates, are significant predictors of suicide, the individual-level characteristics, such as one's unemployment, carry a stronger association (Agerbo, Sterne, \& Gunnell, 2006).

Clinical interviews and surveys enable asking for relevant background details and instant information, such as exposure to suicidal behavior in one's social network (e.g., suicide by family members or friends). While these options are not available in register-based data, impressive multigenerational studies compensate for this by not being subject to informer bias (Niederkrotenthaler, Floderus, Alexanderson, Rasmussen, \& Mittendorfer-Rutz, 2012). Linkage with the multigeneration register and detailed data for a large study population also offers the possibility for bereavement studies using intraindividual designs (Mogensen, Möller, Hultin, \& Mittendorfer-Rutz, 2016). These study designs inherently control for all time-stable confounding factors and thereby limit the risk of unmeasured residual confounding.

Other interesting opportunities arise from linking clinical data, including data from randomized controlled trials (RCTs), to register-based data. This way, reporting bias may also be addressed. For instance, a recent study found a substantial bidirectional divergence between self-reported and hospital records of deliberate self-harm (Morthorst, Krogh, Erlangsen, Alberdi, \& Nordentoft, 2012). Advanced analytical methods based on register data can be used here to model repeated suicide attempts (Mittendorfer-Rutz, Alexanderson, Westerlund, \& Lange, 2014).

\section{Risk Predictor Studies}

Register-based studies have quantified risks of suicidal behavior related to mental disorders and its association with many disorders, including schizophrenia, psychosis, affective (including bipolar) disorders, personality (including borderline) disorders, anxiety disorders, alcohol and substance misuse, attention deficit hyperactivity disorder (ADHD), autism spectrum disorders, and dementia, (Erlangsen, Zarit, \& Conwell, 2008; Ljung, Chen, Lichtenstein, \& Larsson, 2014; Mortensen, Agerbo, Qin, \& Westergaard-Nielsen, 2000; Qin, 2011; Qin \& Nordentoft, 2005). Importantly, findings from register-based studies have demonstrated elevated risks at the time of admission and discharge from a psychiatric hospital, hence pointing out the need for intervention. Also, exposure to mental disorders or suicide in relatives has been confirmed as a predictor of suicidal behavior in population-based register studies (Christiansen, Larsen, Agerbo, Bilenberg, \& Stenager, 2013; Mittendorfer-Rutz, Rasmussen, \& Wasserman, 2008; Qin, Agerbo, \& Mortensen, 2003). Population-wide data have also shown that the absolute risk of suicide among people with schizophrenia, for instance, varied between $6.6(95 \% \mathrm{CI}=5.9-7.3)$ for men and 4.9 (95\% CI $=4.0-6.0)$ for women (Nordentoft, Mortensen, $\&$ Pedersen, 2011).

Various social and economic characteristics have been associated with higher risks of suicide behavior for peo- 
ple who: are not married or in a de facto relationship, receive disability pension, are retired, live in urban areas, are changing residence, have an immigrant background, do not have children, and are exposed to the death of significant others (Burrell, Mehlum, \& Qin, 2017; Jonsson, Alexanderson, Kjeldgård, Westerlund, \& Mittendorfer-Rutz, 2013; Mogensen et al., 2016; Puzo, Mehlum, \& Qin, 2017; Qin, 2005; Qin et al., 2003). Inventive linkage between registers, furthermore, has allowed for the examination of rarely studied associations, such as the relationship between death by suicide and area-level recordings of air pollen (slightly elevated levels of pollen: $\mathrm{RR}=1.07,95 \% \mathrm{CI}=$ 1.01-1.13) and silicone breast implants (SMR $=2.9,95 \%$ CI = 1.6-4.8; Koot, Peeters, Granath, Grobbee, \& Nyren, 2003; Qin, Waltoft, Mortensen, \& Postolache, 2013).

\section{Intervention Studies}

In principle, new treatment regimens, both pharmacological and psychosocial therapies, can be evaluated using register-based data. For instance, a recent study has shown that temazepam and zopiclone/zolpidem from the group of benzodiazepines and hypnotics were considerably more toxic than diazepam (Geulayov et al., 2018). This might be of relevance for policy-makers planning interventions to limit the availability of means for suicide, that is, by restricting access to highly toxic drugs. However, the availability of long-term follow-up data also means that one may study effects on outcomes not usually addressed in clinical interventions, such as death by suicide. By linkage between clinical and register data, it was feasible to generate sufficiently large follow-up material on recipients of the psychosocial therapy provided, for instance, in Danish suicide prevention clinics with statistical strength to assess death by suicide (Erlangsen et al., 2014).

\section{Nordic Linkage}

There are seemingly few boundaries to possible areas and study designs using register-based data. Theoretically, it would even be possible to obtain an individual-level database on $26+$ million inhabitants by merging data across the Nordic countries. The relatively comparable social welfare systems of the Nordic countries would even support coherence in patterns across national borders. In practical terms, however, it seems less likely that this can happen because data regulations in some countries prevent individual-level data being stored physically outside the country. Although a loosening of regulations has taken place over the past few decades, it might take some time before this is feasible.

Still, researchers have not been restricted by these measures. Given that aggregate results from data analyses may be taken out of the country, studies have used this opportunity to combine Danish, Finish, and Swedish register data; for instance, with respect to assessing risks of suicide after bereavement and among persons in same-sex marriages (Erlangsen et al., 2018; Guldin et al., 2015). In some instances, it is feasible to obtain aggregate data sets on number of events, such as suicide, and time of exposure as well as person-years, broken down by relevant covariates. Such data sets may be considered as anonymous in aggregate, thus making it possible to share these across borders with respect to conducting joint regression analysis for several countries.

\section{Safety Considerations}

Needless to say, sensitive data of this type are guarded by heavy security restrictions. All Nordic countries, therefore, have sound legislations and regulations for the utilization of personal data and privacy safeguarding. In order to obtain access to data, both projects and researchers have to be approved by national data protection agencies, ethical review boards, and in some cases by the respective data providers or owners. Typically, researchers access data extracts through secured Internet portals while data are physically stored on a server in protected locations, such as national statistical offices or approved research institutes. It is, furthermore, a requirement that the personal id number is replaced by an anonymous linkage number before data are delivered to specific projects. After legal review, the data are only made available for researchers who meet the criteria for access to these types of sensitive data. These procedures follow the national Ethical Review Acts, the Personal Data Acts, and the Administrative Procedure Acts. As data are derived from different registers, no personal contact with the individuals is established. Results are presented on a group level without any possibility of backward identification. The research groups working with register data also apply high standards of data safety.

\section{Strengths and Limitations}

Strengths of register-based studies are manifold. These include the nationwide coverage that ensures full representativeness. In general, data validity is evaluated favorably. This is supported by an administrative system where 
errors are corrected on a continuous and retrospective basis. Also, having a study population of several millions is beneficial in terms of statistical power when studying relatively rare events, such as death by suicide and deliberate self-harm. Precision in estimates of prevalence and risk is improved by uniformly collected measures and individual-level data. Furthermore, the longitudinal nature of data and having dates on events allow for not only inclusion of time-varying covariates but also time-to-event analysis.

Not everything is marvelous about register-based data; firstly, an obstacle is the lack of information from general practitioners, for example, there is no national coverage in Sweden. Also, in most Nordic countries, electronic recordings of diagnoses given in the general practitioner's office are not available, although this is likely to change in the near future. Next, only persons who actively seek treatment are captured by hospital or medical prescription records. In other words, those who are not diagnosed are not included in the exposure groups, implying that the actual at-risk population is underestimated. This is likely to be a prevalent problem with respect to mental disorders and could potentially introduce selection bias to risk estimates. Also, the validity of diagnoses depends on clinical rigor and assessment tools, which might have improved over time. It is often praised as an advantage that exact dates are available in the registers; however, those dates are typically the date of diagnosis and not the onset of disorders.

\section{Access From Abroad and Lessons Learned}

Foreign researchers can, in principle, obtain access to register-based data, depending on national regulations. In most cases, the easiest way of gaining access would be through collaborations with research institutions in the respective countries.

While data in some countries have to remain stored physically within the borders of the country, the exact regulations vary from one country to another. One of the most important lessons learned from the Nordic register research is the importance of regulated access to and safe storage of data in order to minimize risk of misuse.

\section{Future Avenues}

A lot of ingenuity has gone into examining statistical associations using register-based data and this will certainly continue in coming decades. While international studies have begun to employ machine-learning algorithms and big data, these avenues have yet to be explored in a Nordic setting; it will be interesting to see what data linkage can contribute in this respect. Genetic data have been gathered, also on a population-based level, in several of the Nordic countries. In the Danish iPSYCH project, genetic chips have been coded for a population-based sample as well as for all individuals who have been diagnosed with severe mental disorders, allowing for comprehensive studies of genetic predictors and later epigenetics (Pedersen et al., 2018). Other avenues might lie in the possibility of linkage to yet relatively unexplored registers, such as hospital laboratory tests or electronic patient journals, including analyses of free text fields.

\section{Concluding Remarks}

Nordic registers have contributed substantially to the existing knowledge on high risk-groups with respect to suicidal behavior. It is likely that similar venues might be further explored in other countries; even linkage of relatively few registries might generate a more complete and less biased database than what can be secured through other data sources. The boundaries for register-based research are set by the necessary data protection laws. However, it seems that there are no limits in sight for research options using register-based data to address studies regarding the etiology and prevention of suicidal behavior.

\section{Acknowledgments}

The authors have no conflict of interest to report.

\section{References}

Agerbo, E., Sterne, J. A., \& Gunnell, D. J. (2006). Combining individual and ecological data to determine compositional and contextual socio-economic risk factors for suicide. Social Science and Medicine, 64, 451-61. https://doi.org/10.1016/j. socscimed.2006.08.043

Burrell, L. V., Mehlum, L., \& Qin, P. (2017). Risk factors for suicide in offspring bereaved by sudden parental death from external causes. Journal of Affective Disorders, 222, 71-78. https://doi. org/10.1016/j.jad.2017.06.064

Christiansen, E., Larsen, K. J., Agerbo, E., Bilenberg, N., \& Stenager, E. (2013). Incidence and risk factors for suicide attempts in a general population of young people: A Danish register-based study. Australian and New Zealand Journal of Psychiatry, 47(3), 259-270. https://doi.org/10.1177/0004867412463737

Erlangsen, A., Drefahl, S., Haas, A., Björkenstam, C., Nordentoft, M., \& Andersson, G. (2018). Suicide among persons who entered same-sex and opposite-sex marriage in Denmark and Sweden, 1989-2012: A binational, register-based cohort study. Manuscript submitted for publication 
Erlangsen, A., Lind, B., Stuart, E. A., Qin, P., Stenager, E., Larsen, K. J., ... Nordentoft, M. (2014). Short and long term effects of psychosocial therapy provided to persons after suicide attempt: A register-based, nationwide multicentre study using propensity score matching. The Lancet Psychiatry, 2, 47-58. https://doi. org/10.1016/S2215-0366(14)00083-2

Erlangsen, A., Zarit, S. H., \& Conwell, Y. (2008). Hospital-diagnosed dementia and suicide: A longitudinal study using prospective, nationwide register data. The American Journal of Geriatric Psychiatry, 16, 220-228. https://doi.org/10.1097/ JGP.0b013e3181602a12

Geulayov, G., Ferrey, A., Casey, D., Wells, C., Fuller, A., Bankhead, C., ... Hawton, K. (2018). Relative toxicity of benzodiazepines and hypnotics commonly used for self-poisoning. Journal of Psychopharmacology. Advance online publication. https://doi. org/10.1177/0269881118754734

Guldin, M. B., Li, J., Pedersen, H. S., Obel, C., Agerbo, E., Gissler, M., ... Vestergaard, M. (2015). Incidence of suicide among persons who had a parent who died during their childhood: A population-pased cohort study. JAMA Psychiatry, 72(12), 1227-1234. https://doi.org/10.1001/jamapsychiatry.2015.2094

Jonsson, U., Alexanderson, K., Kjeldgård, L., Westerlund, H., \& Mittendorfer-Rutz, E. (2013). Diagnosis-specific disability pension predicts suicidal behaviour and mortality in young adults: A nationwide prospective cohort study. BMJ Open, 3(2), e002286. https://doi.org/10.1136/bmjopen-2012-002286

Kompetansesenter for IT i helsevesenet. (2010). Identifikatorer for personer. Retrieved from https://ehelse.no/standarderkodeverk-og-referansekatalog/standarder-og-referansekat alog/identifikatorer-for-personer-syntaks-for-fodselsnum mer-hjelpenummer-mv-his-10012010

Koot, V. C. M., Peeters, P. H. M., Granath, F., Grobbee, D. E., \& Nyren, O. (2003). Total and cause specific mortality among Swedish women with cosmetic breast implants: Prospective study. British Medical Journal, 326, 527-528. https://doi.org/10.1136/ bmj.326.7388.527

Ljung, T., Chen, Q., Lichtenstein, P., \& Larsson, H. (2014). Common etiological factors of attention-deficit/hyperactivity disorder and suicidal behavior: A population-based study in Sweden. JAMA Psychiatry, 71(8), 958-964. https://doi.org/10.1001/jamapsychiatry.2014.363

Ludvigsson, J. F., Otterblad-Olausson, P., Pettersson, B. U., \& Ekbom, A. (2009). The Swedish personal identity number: Possibilities and pitfalls in healthcare and medical research. European Journal of Epidemiology, 24(11), 659-667. https://doi. org/10.1007/s10654-009-9350-y

Mittendorfer-Rutz, E., Alexanderson, K., Westerlund, H., \& Lange, T. (2014). Is transition to disability pension in young people associated with changes in risk of attempted suicide? Psychological Medicine, 44(11), 2331-2338. https://doi.org/10.1017/ S0033291713003097

Mittendorfer-Rutz, E., Rasmussen, F., \& Wasserman, D. (2004). Restricted fetal growth and adverse maternal psychosocial and socioeconomic conditions as risk factors for suicidal behaviour of offspring: A cohort study. The Lancet, 364(9440), 1135-1140. https://doi.org/10.1016/S0140-6736(04)17099-2

Mittendorfer-Rutz, E., Rasmussen, F., \& Wasserman, D. (2008). Familial clustering of suicidal behaviour and psychopathology in young suicide attempters. Social Psychiatry and Psychiatric Epidemiology, 43(1), 28-36. https://doi.org/10.1007/s00127007-0266-0

Mogensen, H., Möller, J., Hultin, H., \& Mittendorfer-Rutz, E. (2016). Death of a close relative and the risk of suicide in Sweden - a large scale register-based case-crossover Study. PloS One, 11(10), e0164274. https://doi.org/10.1371/journal. pone. 0164274
Mortensen, P. B., Agerbo, E., Qin, P., \& Westergaard-Nielsen, N. (2000). Psychiatrc illness and risk factors for suicide in Denmark. The Lancet, 355, 9-12.

Morthorst, B., Krogh, J., Erlangsen, A., Alberdi, F., \& Nordentoft, M. (2012). Effect of assertive outreach after suicide attempt in the AID (assertive intervention for deliberate self harm) trial: Randomised controlled trial. British Medical Journal, 345, e4972. https://doi.org/10.1136/bmj.e4972

Niederkrotenthaler, T., Floderus, B., Alexanderson, K., Rasmussen, F., \& Mittendorfer-Rutz, E. (2012). Exposure to parental mortality and markers of morbidity, and the risks of attempted and completed suicide in offspring: An analysis of sensitive life periods. Journal of Epidemiology and Community Health, 66(3), 233-239. https://doi.org/10.1136/jech.2010.109595

Niederkrotenthaler, T., Tinghög, P., Alexanderson, K., Dahlin, M., Wang, M., Beckman, K., ... Mittendorfer-Rutz, E. (2014). Future risk of labour market marginalization in young suicide attempters - a population-based prospective cohort study. International Journal of Epidemiology, 43(5), 1520-1530. https://doi. org/10.1093/ije/dyu155

Nielsen, H. (1991). CPR - Danmarks Folkeregister [The Centralised Civil Register - the population register of Denmark]. Retrieved from https://www.cpr.dk/media/17546/cpr-danmarks-folkereg ister.pdf

Nordentoft, M., Mortensen, P. B., \& Pedersen, C. B. (2011). Absolute risk of suicide after first hospital contact in mental disorder. Archives of General Psychiatry, 68(10), 1058-1064. https://doi. org/10.1001/archgenpsychiatry.2011.113

Population Register Centre, Finland. (2018). History of Finnish population information system. Retrieved from http://vrk.fi/en/ history

Pedersen, C. B., Bybjerg-Grauholm, J., Pedersen, M. G., Grove, J., Agerbo, E., Baekvad-Hansen, M., ... Mortensen, P. B. (2018). The iPSYCH2012 case-cohort sample: New directions for unravelling genetic and environmental architectures of severe mental disorders. Molecular Psychiatry, 23, 6-14. https://doi. org/10.1038/mp.2017.196

Puzo, Q., Mehlum, L., \& Qin, P. (2017). Suicide among immigrant population in Norway: A national register-based study. Acta Psychiatrica Scandinavica, 135(6), 584-592. https://doi. org/10.1111/acps.12732

Qin, P. (2005). Suicide risk in relation to level of urbanicity - a population-based linkage study. International Journal Epidemiology, 34(4), 846-852. https://doi.org/10.1093/ije/dyi085

Qin, P. (2011). The impact of psychiatric illness on suicide: Differences by diagnosis of disorders and by sex and age of subjects. Journal of Psychiatric Research, 45(11), 1445-1452. https://doi. org/10.1016/j.jpsychires.2011.06.002

Qin, P., Agerbo, E., \& Mortensen, P. B. (2003). Suicide risk in relation to socioeconomic, demographic, psychiatric and familial factors: A national register-based study of all suicides in Denmark, 1981-1997. The American Journal of Psychiatry, 160, 765-772. https://doi.org/10.1176/appi.ajp.160.4.765

Qin, P., \& Nordentoft, M. (2005). Suicide risk in relation to psychiatric hospitalization: Evidence based on longitudinal registers. Archives of General Psychiatry, 62(4), 427-432. https://doi. org/10.1001/archpsyc.62.4.427

Qin, P., Waltoft, B. L., Mortensen, P. B., \& Postolache, T. T. (2013). Suicide risk in relation to air pollen counts: A study based on data from Danish registers. BMJ Open, 3(5). https://doi.org/10.1136/ bmjopen-2012-002462

Watson, I. (2010). A short history of national identification numbering in Iceland. Bifröst Journal of Social Science, 4, 51-88. 
Accepted April 12, 2018

Published online May 24, 2018

Annette Erlangsen, PhD, is Program Leader and Associate Professor at the Danish Research Institute for Suicide Prevention. She is a visiting researcher at the Centre for Mental Health Research, Australian National University, and Adjunct Associate Professor at the Department of Mental Health, Johns Hopkins Bloomberg School of Public Health, USA.

Ping Qin, MD, PhD, is Professor at the National Centre for Suicide Research and Prevention, University of Oslo, Norway, and Head of the research group for the register-based studies on suicide and deliberate self-harm. She is also Distinguished Visiting Professor at Shandong
University, China, and current Vice-President of the International Association for Suicide Prevention.

Ellenor Mittendorfer-Rutz, PhD, is Associate Professor and research group leader at Karolinska Institutet, Stockholm, Sweden. She is also a guest professor at the Medical University Vienna, Austria.

\section{Annette Erlangsen}

Danish Research Institute for Suicide Prevention

Kildegaardsvej 28

2900 Hellerup

Denmark

annette.erlangsen@regionh.dk 